\title{
Left intracardiac thrombosis: An exceptional complication revealing BehCet's disease
}

\author{
Mounira El Euch, Ben Fredj Ismail Fatma, Rezgui Amel, Karmani Monia, Derbali Fatma, \\ Amri Raja, Laouani Kechrid Chedia
}

Department of Internal Medicine, Sahloul University Hospital, Sousa, Tunisia

Email: ach_mounira@hotmail.com, bfi.fatma@yahoo.fr, rezguiamel@yahoo.fr, moniakarmani@yahoo.fr, derbalifatma@yahoo.fr, raja.elamri@yahoo.fr, chedia.kechrid@rns.tn

Received 30 December 2011; revised 6 February 2012; accepted 24 February 2012

\begin{abstract}
Although cardiac involvement during Behcet syndrome is uncommon and intracardiac thrombosis is exceptional, it concerns the right ventricle much more than the left one. We report an illustrative case of left intracardiac thrombosis revealing Behcet's disease in a 33-year-old Tunisian man.
\end{abstract}

Keywords: Behcet’s Disease; Cardiac Involvement; Thrombosis

\section{BACKGROUND}

Behcet syndrome is a multisystemic, chronic, inflammatory disorder of unknown cause. It is characterized by recurrent buccalaphthosis, genital ulcers, and uveitis with hypopyon. Although its etiology is unknown, it is likely due to an autoimmune vasculitis in genetically predisposed individuals triggered by an infectious agent or other antigens [1,2]. Behcet's Disease mostly affects children and young adults between the second and fourth decades of life [3]. Those affected before the age of 25 years (early onset) and males have been shown to have more severe disease symptoms [4]. Additional manifestations in other locations (skin, joints, gastrointestinal tract, genitourinary tract, central nervous system, cardiovascular system, and lungs) can appear and can influence the clinical course and prognosis. Although cardiac involvement during Behcet syndrome is uncommon and intracardiac thrombosis is exceptional, and concerns the right ventricle much more than the left one.

Young men originating from Mediterranean basin and Middle East appear to be most at risk. We report here an illustrative case of left intracardiac thrombosis revealing Behcet's disease in a 33-year-old Tunisian man.

\section{CASE REPORT}

A 33-year-old Tunisian man with a history of recurrent oral aphtosis during five months, progressively developed fever, chest pain and weight loss. Echocardiography showed a heterogeneous and mobile mass in the left ventricle apex (Figures 1 and 2). The patient was thought to have infective endocarditis and was given antibiotics. There was no improvement and blood cultures remained negative. A few days later, he presented a genital aphtosis, right hemiparesis, headache and vomiting.

The CT scan disclosed a left occipito-parietal lesion with important oedema, consistent with a cerebral embolus. Cardiac MRI showed abnormal endocardium enhanced signal of left ventricle apex (Figures 3 and 4).

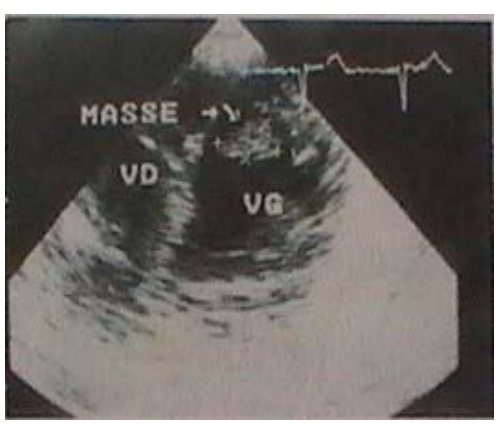

Figure 1. Transthoracic echocardiography showing a heterogeneous mass in the left ventricle apex.

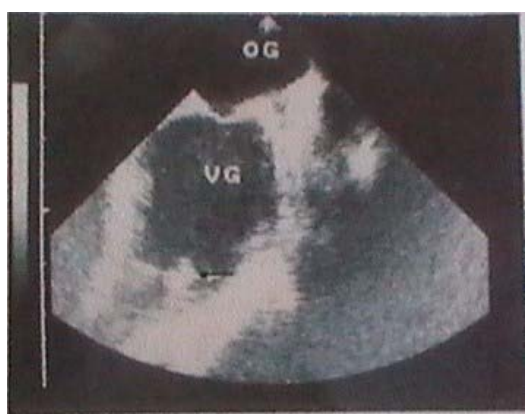

Figure 2. Transoesophageal echocardiography showing a heterogeneous mass in the left ventricle apex. 


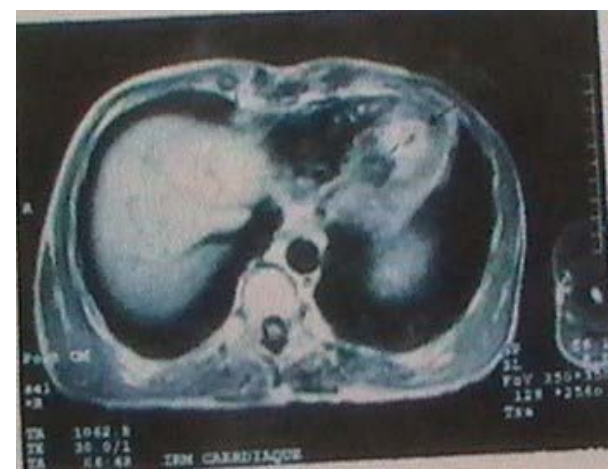

Figure 3. Axial cardiac MRI showing an endocardium enhanced signal in the left ventricle.

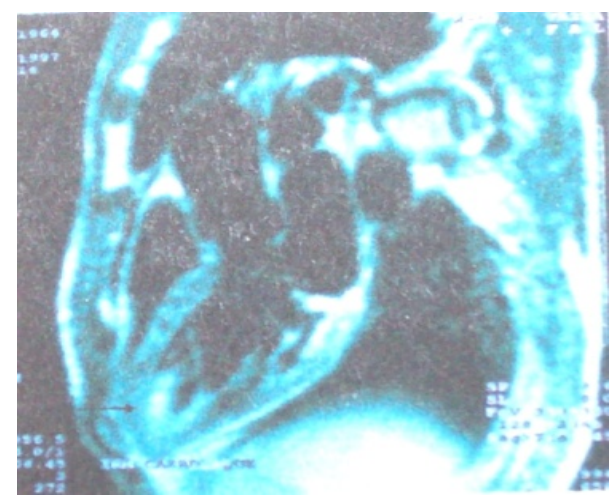

Figure 4. Para sagittal cardiac MRI showing an enhanced signal in the left ventricle apex endocardium.

Cerebral MRI showed multiple ischemic lesions: left occipito-parietal cortex (Figure 5), right caudate nucleus Figure 6), right cerebellar cortex (Figure 7) and cerebellar peduncle (Figure 8).

The patient was referred to heart surgery and a $1.5 \mathrm{~cm}$ mass was removed from the left ventricle and histological examination showed a thrombus with inflammatory endocardium. In the light of orogenitalaphtosis, neurological lesions and intracardiac thrombosis, a Behcet's disease was strongly suspected (Table 1). The patient was given colchicine, high-dose Prednisone and anticoagulant therapy; he improved and had no neurological sequelae.

Two years later, a control echocardiography showed a pseudo aneurysm of the left ventricle measuring $5 \mathrm{~cm}$, near the ventriculotomy scar. The patient underwent a successful surgical treatment. He is currently doing well, seven years after the second heart surgery.

\section{DISCUSSION}

The prevalence of vascular involvement in Behcet syndrome varies from $7.7 \%$ to $43 \%$, in accordance with the ethnicity of the population under study [5].

Our patient fulfilled the proposed criteria of the inter-

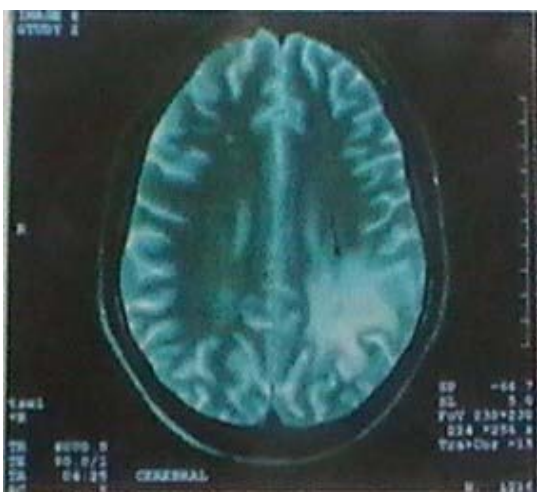

Figure 5. Cerebral T2 weighted MRI disclosing left occipito-parietal lesion.

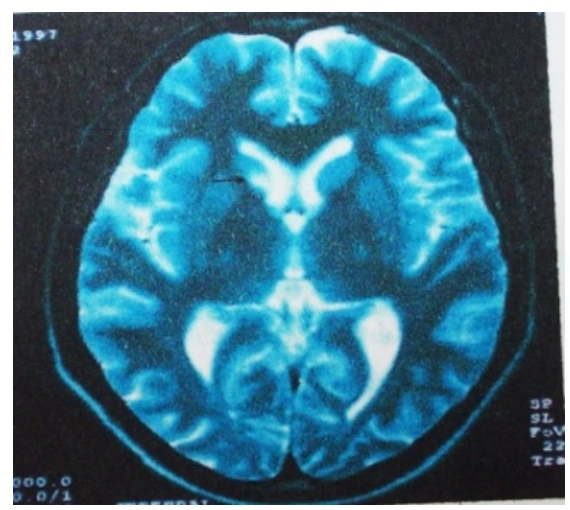

Figure 6. Cerebral T2 weighted MRI showing right caudate nucleus ischemic lesion.

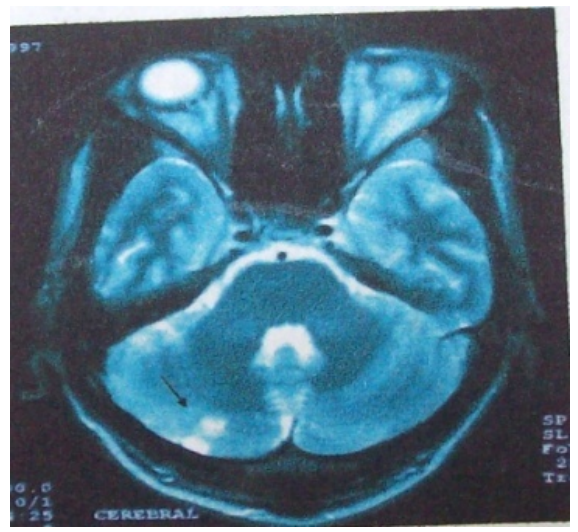

Figure 7. Cerebral T2 weighted MRI showing right cerebellar ischemic lesion.

national study group for BD [6].

The pathogenic mechanism underlying the thrombotic tendency among patients with Behçet syndrome is not well known. Several causal factors have been suggested:

- Endothelial cell ischemia or disruption, which leads to enhancement of platelet aggregation [7-9].

- The presence of antiphospholipid antibodies, which is reported to occur in $18 \%$ of cases [7-9].

- The presence of prothrombotic factors, such as defi- 
ciencies of protein $\mathrm{S}$, protein $\mathrm{C}$, and antithrombin [10].

- Elevated von Willebrand factor antigen levels, which have recently been observed in association with Behçet syndrome [11].

- Fibrinolysis anomaly due to endothelial cell damage after the deposition of antigen-antibody (immune complex disease) [12,13].

- Homozygosis for the factor V Leiden mutation or the prothrombin gene, which increases the risk of thrombosis by a factor of 6 or 3, respectively [9-11].

Thrombosis is the most frequent lesion [14]. Usually, arterial thrombosis occurs later than does venous thrombosis [15]. Thrombosis is very often associated with (and predictive of) ocular involvement in Behcet syndrome [6]. Despite the high incidence of vascular damage in this disease (more than one third of patients experience it); cardiac involvement is uncommon [16]. It varies from $1 \%$ to $5 \%$ in clinical series and was $16.5 \%$ in a register of Behcet autopsy cases in Japan [7]. Cardiac involvements consist of cardiomegaly, endocarditis or pericarditis and less commonly of myocardial infarction and myocarditis. Association with intracardiac thrombus which is a serious complication is even more rare. From the 1st description by Buge in 1977 [17] through Ham-

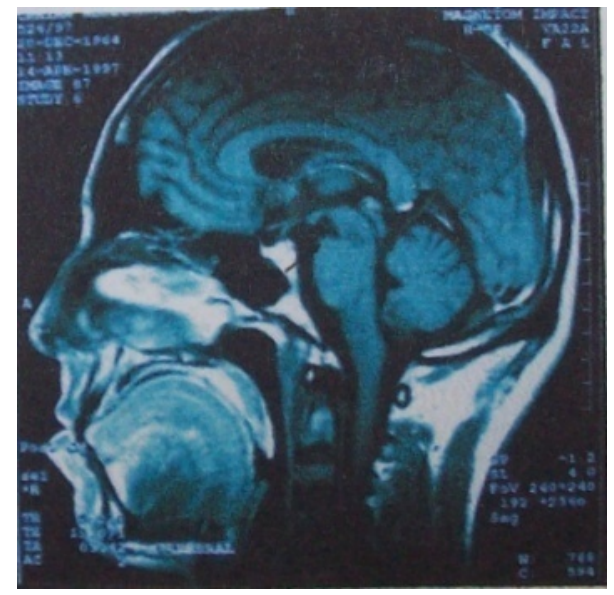

Figure 8. Cerebral T1 weighted MRI showing peduncular lesion.

Table 1. criteriapresented by the patient for diagnosis of Behçet's syndrom.

\begin{tabular}{cc}
\hline Met criteria & Unmet criteria \\
\hline Age & Pathergy test \\
Sex & Cutaneous features \\
Oro genital aphtosis & Eye inflammation \\
Neurological lesions & \\
Cardiac thrombosis & \\
\hline
\end{tabular}

mami's brief review of the literature in 2005, nine only about 50 cases had been reported, some associated with endomyocardial fibrosis and some not. The appearance of such thrombi often precedes other manifestations of Behcet syndrome, and it is rarely inaugural [18]. Intracardiac thrombus is associated with deep vein thrombosis and with thrombosis of the vena cava, respectively, in $50 \%$ and $22 \%$ of cases $[7,18,19]$. Thrombus can also be associated with an aneurysm of the pulmonary artery, or with endomyocardial fibrosis [20].

Transesophageal and transthoracic echocardiography are generally sufficient to enable a diagnosis of cardiac thrombosis. The mass is usually heterogeneous and echogenic, involving the ventricles rather than the atria [19] and the right heart more often than the left [7]. In our case report, the thrombus was found in the left ventricle. Ultrasonic imaging might suggest a differential diagnosis-a large vegetation, for example, or an intracardiac tumor such as a myxoma, or endomyocardial fibrosisbut the clinical context helps to clarify the diagnosis [21]. In any event, the resolution of the mass under anticoagulant or antiplatelet therapy establishes a retrospective diagnosis, because it distinguishes thrombus from tumor [7].

There is no consensus regarding the treatment of cardiac thrombosis in association with Behcet syndrome. The aim of treatment is to control the underlying disease and to resolve the cardiac thrombus. Anticoagulant and antithrombotic agents are the 1st line of therapy [9]. However, an associated aneurysm of the pulmonary artery-especially the presence of large or bilateral aneurysms-makes the use of these therapies difficult because of the risk of a devastating hemoptysis. Surgery might become necessary in cases of cardiac thrombosis that is massive, is recurrent after medical treatment, or is associated with cardiac congestion [22].

\section{CONCLUSION}

Left cardiac thrombus formation is exceptional in Behcet's disease. It may clinically present as cardiac tumor or as infective endocarditis. Its discovery precedes, in half of cases, the diagnosis of Behcet's disease. Diagnosis is often established intra-operatively. Medical treatment includes colchicine, corticosteroids, anticoagulant and eventually immunosuppressive drugs. This should be preferred to surgery which may be complicated by pseudo aneurysm. This case showed that thrombi, especially in the left-heart cavities, are possible complications of Behcet syndrome that can lead to pulmonary embolism. Early echocardiography is advisable for the detection of cardiac involvement, and medical treatment should be the first choice of therapy.

In spite of the low prevalence of Behcet's disease and the rare additional condition of intracardiac thrombosis, it should be taken into account when a young Mediterra- 
nean male patient has an intracardiac mass, due to the severity of the condition and need for early treatment.

\section{REFERENCES}

[1] Ebert, E.C. (2009) Gastrointestinal manifestations of Behçet's disease. Digestive Diseases and Sciences, 54, 201207. doi:10.1007/s10620-008-0337-4

[2] Barlas, S. (1999) Behçet’s disease. An insight from a vascular surgeon's point of view. Acta Chirurgica Belgica, 99, 274-281.

[3] Koné-Paut, I., Yurdakul, S., Bahabri, S.A., Shafae, N., Ozen, S., Ozdogan, H., et al. (1998) Clinical features of Behçet's disease in children: An international colloborative study of 86 cases. The Journal of Pediatrics, 132, 721-725. doi:10.1016/S0022-3476(98)70368-3

[4] Yazici, H., Tüzün, Y., Pazarli, H., Yurdakul, S., Ozyazgan, Y., Ozdoan, H., et al. (1984) Influence of age of onset and patient's sex on the prevalance and severity of manifestations of Behçet's syndrome. Annals of the Rheumatic Diseases, 43, 783-789. doi:10.1136/ard.43.6.783

[5] Ames, P.R., Steuer, A., Pap, A. and Denman, A.M. (2001) Thrombosis in Behcet's disease: A retrospective survey from a single UK centre. Rheumatology, 40, 652-655. doi:10.1093/rheumatology/40.6.652

[6] International Study Group for Behçet's Disease (1990) Criteria for diagnosis of Behçet's disease. Lancet, 335, 1078-1080

[7] Wechsler, B., Du, L.T. and Kieffer, E. (1999) Cardiovascular manifestations of Behcet's disease. Ann Med Interne, 150, 542-554.

[8] Baykan, M., Celik, S., Erdol, C., Baykan, E.C., Durmus, I., Bahadir, S., et al. (2001) Behcet's disease with a large intracardiac thrombus: A case report. Heart, 85, E7. doi:10.1136/heart.85.4.e7

[9] Mogulkoc, N., Burgess, M.I. and Bishop, P.W. (2000) Intracardiac thrombus in Behcet's disease: A systematic review. Chest, 118, 479-487. doi:10.1378/chest.118.2.479

[10] Akar, N. (1998) Site specific mutagenesis: Usage for the mutation detection in thrombosis. Turkish Journal of Hematology, 15, 123-124.

[11] Kiraz, S., Ertenli, I., Ozturk, M.A., Haznedaroglu, I.C., Celik, I. and Calguneri, M. (2002) Pathological haemostasis and "prothrombotic state" in Behcet's disease. Thrombosis Research, 105, 125-133. doi:10.1016/S0049-3848(02)00006-3

[12] Gul, A., Ozbek, U., Ozturk, C., Inanc, M., Konice, M. and Ozcelik, T. (1996) Coagulation factor V gene mutation increases the risk of venous thrombosis in Behcet's disease. British Journal of Rheumatology, 35, 1178-1180. doi:10.1093/rheumatology/35.11.1178

[13] Hammami, S., Mahjoub, S., Ben-Hamda, K., Brahem, R., Gamra, H. and Ben, F.M. (2005) Intracardiac thrombus in Behcet's disease: Two case reports. Thrombosis Journal, 3, 9. doi:10.1186/1477-9560-3-9

[14] Houman, M.H., Ben, G.I., Khiari, B.S.I, Lamloum, M., Ben, A.M. and Miled, M. (2001) Deep vein thrombosis in Behcet's disease. The Clinical and Experimental Rheumatology, 19, S48-S50.

[15] Harmouche, H., TaziMezalek, Z., Adnaoui, M., Aouni, M., Mohattane, A., Maaouni, A. and Berbich, A. (1998) Association of pulmonary artery aneurysm, right heart thromboses and antiphospholipid antibodies in Behcet's disease. Revue de Médecine Interne, 9, 512-515. doi:10.1016/S0248-8663(99)80009-5

[16] Koc, Y., Gullu, I., Akpek, G., Akpolat, T., Kansu, E., Kiraz, S., et al. (1992) Vascular involvement in Behcet's disease. Journal of Rheumatology, 19, 402-410.

[17] Buge, A., Escourolle, R., Chomette, G., Rancurel, G., Dechy, H., Hauw, J.J., et al. (1977) Behcet's disease with neurologic manifestations and endocardial fibrosis of the right heart. Anatomoclinical study of a case. Annals of the Medical Interne, 128, 411-419.

[18] el-Ramahi, K.M., Fawzy, M.E., Sieck, J.O. and Vanhaleweyk, G. (1991) Cardiac and pulmonary involvement in Behcet's disease. Scandinavian Journal of Rheumatology, 20, 373-376. doi:10.3109/03009749109096815

[19] Islim, I.F., Gill, M.D., Situnayake, D. and Watson, R.D. (1994) Successful treatment of right a trial thrombus in a patient with Behcet's disease. Annals of the Rheumatic Diseases, 53, 550-551. doi:10.1136/ard.53.8.550-b

[20] Houman, M., Ksontini, I., Ben, G.I., Lamloum, M., Braham, A., Mnif, E. and Miled, M. (2002) Association of right heart thrombosis, endomyocardial fibrosis, and pulmonary artery aneurysm in Behcet's disease. European Journal of Internal Medicine, 13, 455. doi:10.1016/S0953-6205(02)00134-6

[21] Marc, K., Iraqui, G., Jniene, A., Benamor, J. and Bourkadi, J.E. (2008) Intracardiac thrombus and pulmonary artery aneurysm in Behcet's disease. Revue des Maladies Respiratoires, 25, 69-72. doi:10.1016/S0761-8425(08)70469-8

[22] Darie, C., Knezinsky, M., Demolombe-Rague, S., Pinede, L., Perinetti, M., Ninet, J.F. and Ninet, J. (2005) Cardiac pseudotumor revealing Behcet's disease. Revue de Médecine Interne, 26, 420-424. doi:10.1016/j.revmed.2004.12.015 